\title{
Type 3 lodothyronine Deiodinase: Cloning, In Vitro Expression, and Functional Analysis of the Placental Selenoenzyme
}

\author{
Domenico Salvatore, * Susan C. Low, * Marla Berry, * Ana Luiza Maia, * John W. Harney, * Walburga Croteau, ${ }^{\star}$ \\ Donald L. St. Germain, ${ }^{\star}$ and P. Reed Larsen* \\ *Thyroid Division, Department of Medicine, Brigham and Women's Hospital and Harvard Medical School, Boston, Massachusetts \\ 02115; and ${ }^{\ddagger}$ Departments of Medicine and Physiology, Dartmouth Medical School, Lebanon, New Hampshire 03756
}

\begin{abstract}
Type 3 iodothyronine deiodinase (D3) catalyzes the conversion of $T_{4}$ and $T_{3}$ to inactive metabolites. It is highly expressed in placenta and thus can regulate circulating fetal thyroid hormone concentrations throughout gestation. We have cloned and expressed a 2.1-kb human placental D3 cDNA which encodes a 32-kD protein with a $K_{\mathrm{m}}$ of $1.2 \mathrm{nM}$ for 5 deiodination of $\mathrm{T}_{3}$ and $340 \mathrm{nM}$ for $5^{\prime}$ deiodination of reverse $T_{3}$. The reaction requires DTT and is not inhibited by $6 n$-propylthiouracil. We quantitated transiently expressed $D 3$ by specifically labeling the protein with bromoacetyl [ $\left.{ }^{125} \mathrm{I}\right] \mathrm{T}_{3}$. The $K_{\text {cat }} / K_{\mathrm{m}}$ ratio for 5 deiodination of $T_{3}$ was over 1,000 -fold that for $5^{\prime}$ deiodination of reverse $T_{3}$. Human D3 is a selenoenzyme as evidenced by $(a)$ the presence of an in frame UGA codon at position 144, (b) the synthesis of a $32-\mathrm{kD}^{75} \mathrm{Se}$-labeled protein in D3 cDNA transfected cells, and $(c)$ the presence of a selenocysteine insertion sequence element in the $3^{\prime}$ untranslated region of the mRNA which is required for its expression. The D3 selenocysteine insertion sequence element is more potent than that in the type 1 deiodinase or glutathione peroxidase gene, suggesting a high priority for selenocysteine incorporation into this enzyme. The conservation of this enzyme from Xenopus laevis tadpoles to humans implies an essential role for regulation of thyroid hormone inactivation during embryological development. (J. Clin. Invest. 1995. 96:2421 2430.) Key words: iodide peroxidase $\bullet$ thyroxine $\cdot$ thyroid hormones • selenium • selenocysteine
\end{abstract}

\section{Introduction}

Thyroid hormone is critical to the normal development of the human central nervous system (CNS). ${ }^{1}$ Despite the presence Address correspondence to P. Reed Larsen, Thyroid Division, Brig-
ham and Women's Hospital and Harvard Medical School, Boston,
MA 02115. Phone: 617-732-6762; FAX: 617-731-4718; E-mail:
larsen@ rascal.med.harvard.edu
Received for publication 26 June 1995 and accepted in revised form
7 August 1995.

1. Abbreviations used in this paper: $\mathrm{BrAc}$, bromoacetyl; CNS, central nervous system; D1, type 1 iodothyronine deiodinase; D3, type 3 idodothyronine deiodinase; GH, growth hormone; GTG, gold thioglucose; h, human; HEK, human embryonic kidney; nt, nucleotide; PE, phosphate/ EDTA buffer; PTU, $6 n$-propylthiouracil; SECIS, selenocysteine insertion sequence; SE1 D, selenophosphate synthetase, TK, thymidine kinase; ut, untranslated.

J. Clin. Invest.

(C) The American Society for Clinical Investigation, Inc.

$0021-9738 / 95 / 11 / 2421 / 10 \$ 2.00$

Volume 96, November 1995, 2421-2430 of thyroxine $\left(\mathrm{T}_{4}\right)$ and thyroid follicles in the fetal thyroid by 10-12 wk of gestation as well as the potential availability of maternal thyroid hormone, the free concentration of the active thyroid hormone, 3,5,3'-triiodothyronine $\left(\mathrm{T}_{3}\right)$, is less than half that of maternal levels up to the time of delivery $(1-3)$. The physiological rationale for this circumstance is not well understood but is thought to permit the precise timing and regulation of $\mathrm{T}_{3}$ delivery to the CNS by coordination of the expression and action of the type $25^{\prime}$-iodothyronine deiodinase (for review see reference 4 ). This enzyme uses tissue $T_{4}$ as a substrate to produce $T_{3}$ locally and is the primary source of $T_{3}$ for this organ (5). It is also possible that normal circulating $T_{3}$ concentrations could have deleterious effects on immature tissues or could enhance the metabolic requirements of the fetus.

There are two principal mechanisms by which the circulating fetal $T_{3}$ concentration is maintained at low levels. One is that the type 1 iodothyronine deiodinase (D1) in fetal liver is expressed at low levels relative to those in adult life (for review see references 6 and 7 ). This reduces the extrathyroidal $T_{3}$ supply from this source. The second important factor in maintaining low serum $\mathrm{T}_{3}$ concentrations is the expression of high levels of the type 3 deiodinase (D3) in placenta of all species so far examined (for review see references 4, 6-8). This deiodinase catalyzes the inner ring deiodination of $\mathrm{T}_{3}$ and $\mathrm{T}_{4}$ inactivating circulating iodothyronines as well as minimizing transplacental passage of maternal hormone. D3 activity is also expressed in brain, especially in the rat fetus, in fetal rat skin and intestine, as well as in embryonic chick liver $(6,7)$. In humans, placental D3 is sufficiently potent that instillation of $700 \mu \mathrm{g}$ of $\mathrm{T}_{4}$ into amniotic fluid at term causes insignificant increases in the neonatal serum $\mathrm{T}_{3}$ concentration assessed $24 \mathrm{~h}$ later (9).

The cDNAs encoding the D1 enzymes of several species have been cloned, and all have been shown to contain the rare amino acid selenocysteine (10-12). The requirement for selenium in the active center of this enzyme for maximum activity can explain the increased ratio of $T_{4}$ to $T_{3}$ in the circulation and the significant decrease in D1 activity in the liver and kidney of rats made selenium deficient $(13,14)$. However, selenium deficiency has no effect on placental D3 activity nor can a selenium-labeled protein be identified in rat placental microsomes $(15,16)$. This has led to the conclusion that this enzyme does not contain selenocysteine. On the other hand, St. Germain et al. recently identified a $\mathrm{T}_{3}$-responsive cDNA found in Xenopus laevis tadpoles as one encoding a D3 enzyme (XD3) (17). The XD3 protein is $50 \%$ identical to rat D1 and contains an in frame UGA codon and selenocysteine insertion sequence (SECIS) element in the $3^{\prime}$-untranslated region of the mRNA (17). A SECIS element is a stem loop sequence which is required for suppression of the stop codon function of UGA and the insertion of selenocysteine (18). We undertook the present studies to identify the human D3, to establish whether it is, or is not, a selenoenzyme and analyze its tissue expression and catalytic function. 


\section{Methods}

Materials. Two cDNA libraries were used. The first was a human placenta cDNA library in a CDM-8 vector prepared according to the methods of Aruffo and Seed (20), and kindly provided by Dr. Brian Seed (Massachusetts General Hospital, Boston, MA). The second, a human placenta cDNA library in $\lambda$-Zap II, was purchased from Stratagene Inc. (La Jolla, CA). Bromoacetylchloride was from Aldrich Chemical Co. (Milwaukee, WI). ${ }^{125}$ I-labeled 3,3', $5^{\prime}$-triiodothyronine $\left(\mathrm{rT}_{3}\right)$ and $\left.{ }^{125} \mathrm{I}\right]$ 3,5,3' triiodothyronine were from DuPont-NEN (Boston, MA). [ $\left.{ }^{75} \mathrm{Se}\right]$ Selenite was a generous gift of Dr. Dolph Hatfield (National Institutes of Health, Bethesda, MD) and was originally obtained from Dr. Kurt Zinn (University of Missouri Research Reactor, Columbia, MO). All other chemicals were of reagent grade.

Isolation of a human D3 cDNA. Based on sequence homology between rat D1 cDNA and Xenopus laevis D3 cDNA, we prepared two degenerate oligos, sense No. 1 AT(CT)TT(CT)GG(AGCT) (AT)(GC) (AGCT)TG(CT) AC(ACGT)TG(CT)CC and antisense No. 2 (AG)TG(AGCT)GC(CT)TC(CT) TC(AGT)AT(AG)TA(AGT)AT (AGT)AT. We used these oligos in a reverse transcriptase-PCR reaction with $2 \mu \mathrm{g}$ of human placental poly (A) ${ }^{+}$RNA as template. Total RNA was prepared from human placenta using the guanidium method (19). Poly (A) ${ }^{+}$RNA was isolated by chromatography on oligo(dt) cellulose type 7 (Pharmacia LKB Biotechnology, Inc., Piscataway, $\mathrm{NJ}$ ). We amplified a fragment 120 bp long using the above oligos and subcloned this into pBluescript (pBS, Stratagene Inc.). The nucleotide sequence of this fragment had $72 \%$ identity to the XD3. Based on this sequence, two specific oligos (sense No. 3 and antisense No. 4) were synthesized for use with the placental library to obtain the full-length cDNA. The initial PCR amplification was with either oligo No. 3 or No. 4 and a CDM-8 vector-specific oligo. This amplification produced a band 812 bp long which contained $580 \mathrm{bp}$ of sequence similar to the $5^{\prime}$ portion of the $\mathrm{XD} 3$, but the same strategy was not successful for cloning the $3^{\prime}$ portion of the cDNA. We therefore screened a different human placental cDNA library (cloned in $\lambda$ ZAPII; Stratagene Inc.) using the subcloned 812-bp $5^{\prime}$ fragment as a probe. From a total of $\sim 900,000$ recombinants, five positive clones were isolated, one of which corresponded to the full-length cDNA. This was also subcloned into $\mathrm{pBS}$.

Northern blotting. A multiple-tissue Northern blot (Clontech Laboratories, Palo Alto, CA) containing $2 \mu \mathrm{g}$ of poly(A) ${ }^{+}$RNA from a number of normal human tissues was hybridized with $\mathrm{hD} 3$ full-length cDNA following the directions of the manufacturer and autoradiographed. The brain sample was derived from a whole normal adult human brain processed for mRNA extraction.

Isolation of a partial human D3 genomic clone and S1 analysis. A human placenta genomic library in $\lambda$-Fix II (Stratagene Inc.) was screened by hybridization using as probe a 180 -bp fragment corresponding to the $5^{\prime}$ end of the hD3 cDNA (PstI/SacI fragment). DNA from two of five positive clones was mapped after digestion with appropriate restriction enzymes by Southern hybridization. DNA fragments were subcloned into $\mathrm{pBS}$ and sequenced by the dideoxy chain termination method using Sequenase Version 2.0 (United States Biochemical Corp., Cleveland, $\mathrm{OH})$. Poly $(\mathrm{A})^{+}$RNA from human placenta was purified as described before. The $5^{\prime}$ end of the $\mathrm{hD} 3$ gene transcript was determined by $\mathrm{S} 1$ analysis as described (19). A 23-nucleotide (nt) primer complementary to the -62 to -42 bp sequence $5^{\prime}$ to the $A$ of the initiator ATG (CCGACCACCAACCGCGACGTG) was end labeled with [ $\gamma$ ${ }^{32} \mathrm{P}$ ]ATP and $\mathrm{T}_{4}$ nucleotide kinase (Pharmacia). The template for the synthesis of the single-stranded probe was a $\sim 600$-bp genomic fragment with its $3^{\prime}$ border 178 bp downstream of the ATG. After the annealing, the extension reaction and the isolation of a single-stranded 350 -nt probe, an amount of probe equal to $5 \times 10^{4}$ Cerenkov counts was hybridized with $10 \mu \mathrm{g}$ placental Poly (A) ${ }^{+}$RNA for $14 \mathrm{~h}$. The next day, digestion was performed using S1 nuclease (New England Biolabs Inc., Boston, MA) and the product analyzed on a $6 \%$ polyacrylamide, 8.3 $\mathrm{M}$ urea gel in parallel with a sequencing reaction generated with the extension primer.
Preparation of $h D 3, X D 3$, and SelD vectors for eukaryotic expression. To confirm that this clone encoded the type 3 deiodinase, a 1.9$\mathrm{kb}$ insert containing $35 \mathrm{bp}$ of $5^{\prime}$ untranslated (ut) region (186-2066) (Fig 1) was excised from pBluescript and inserted into the Xhol/NotI sites of CDM-8, a mammalian expression vector (20). The same construct was then prepared with the Xenopus D3 cDNA (XD3), kindly provided by Drs. Robert A. Schwartzman and Donald D. Brown of Carnegie Institution (Baltimore, MD), that was excised from pBS with EcoRI/Xhol restriction enzymes and subcloned into the same site of the D10 eukaryotic expression vector (21).

The human selenophosphate synthetase ( Sel D), the homologue of the bacterial enzyme (22), has recently been cloned (23). Its cDNA was also subcloned into CDM- 8 as described.

DNA transfections. Transfection of human embryonic kidney (HEK)-293 cells was by calcium phosphate precipitation as described previously (24). $2 \mathrm{~d}$ after transfection, cells were harvested and sonicated in $0.1 \mathrm{M}$ potassium phosphate, $1 \mathrm{mM}$ EDTA, pH 6.9, (phosphate/ EDTA buffer [PE] buffer), containing $25 \mathrm{mM}$ DTT. Transfection efficiencies were monitored by assay of human growth hormone $(\mathrm{GH})$ in the media derived by cotransfecting a constitutive thymidine kinase (TK) promoter-directed human growth hormone-expressing plasmid, pTKGH (25). Kinetic studies and affinity labeling were performed using aliquots of the same sonicates.

Deiodinase assays. For 5' deiodinase assay, reactions contained 5-

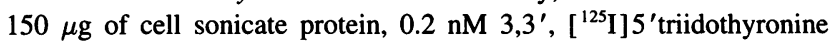
( reverse $\mathrm{T}_{3}$ or $\mathrm{rT}_{3}$ ) purified by LH-20 chromatography, varying concentrations of unlabeled reverse $T_{3}$ or other reagents as indicated and 10 mM DTT in PE buffer in a final volume of $300 \mu \mathrm{l}$. Incubations were for 60 or $120 \mathrm{~min}$ at $37^{\circ} \mathrm{C}$. ${ }^{125} \mathrm{I}$ was separated by TCA precipitation after addition of horse serum as described (26). Deiodination was linear with both protein and time and the quantity of protein assayed was adjusted to consume $<30 \%$ of substrate. All reactions were in duplicate, and all experiments were performed at least twice, with similar results. For the determination of 5 deiodinase activity reaction mixtures contained $1-20 \mathrm{nM}\left[{ }^{125} \mathrm{I}\right] 3,5,3^{\prime}$,triiodothyronine, varying concentrations of DTT, unlabeled $\mathrm{T}_{3}$, or other reagents as indicated. [ $\left.{ }^{125} \mathrm{I}\right] \mathrm{T}_{3}$ was purified by chromatography using Sephadex LH20 (Sigma Chemical Co., St. Louis, MO) before use. The labeled compounds present in the reaction mixture were separated for quantification by ascending paper chromatography (27). Data were quantified and values for $V_{\max }$ and $K_{\mathrm{m}}$ estimated using double reciprocal plots as previously described (17). Data were subjected to one-way ANOVA, and statistical differences among groups were determined using Duncan's multiple range test (28).

Bromoacetyl ( $\mathrm{BrAc})\left[^{125} \mathrm{I}\right] \mathrm{T}_{3}$ affinity labeling and enzyme quantitation. $\mathrm{BrAc}\left[{ }^{125} \mathrm{I}\right] \mathrm{T}_{3}$ was synthesized from bromoacetylchloride and $\mathrm{T}_{3}$ as described previously (29). The product was purified on LH-20 Sephadex by elution with ethanol and purity verified by thin layer chromatography in ethyl acetate/glacial acetic acid (9:1), and the concentration of the product was determined from the specific activity of the $T_{3}$ used in the starting material as described previously. In some experiments, labeled $\mathrm{BrAcT}_{3}$ was diluted with 0.01-3.0 pmol of unlabeled $\mathrm{BrAcT}_{3}$ synthesized in the same manner. In each reaction $0.05 \mathrm{mCi}(\sim 10 \mathrm{fmol})$ of $\mathrm{BrAc}\left[{ }^{125} \mathrm{I}\right] \mathrm{T}_{3}$ was incubated $10 \mathrm{~min}$ at room temperature with 100 $\mu \mathrm{g}$ of cell sonicate protein in $50 \mu \mathrm{l} \mathrm{PE}$ and $10 \mathrm{mM}$ DTT. Reactions were terminated by addition of gel loading buffer containing SDS and $\beta$-mercaptoethanol, followed by boiling for $2 \mathrm{~min}$. Samples were analyzed by SDS-PAGE and autoradiography. The regions of the gel corresponding to the D3 enzyme protein were excised and counted. Equivalent regions were counted from gel lanes containing CDM-8 vectortransfected sonicates and the nonspecific counts subtracted from total counts incorporated. The quantity of enzyme was determined by saturation analysis after plotting the ratio of $\mathrm{BrAc}\left[{ }^{125} \mathrm{I}\right] \mathrm{T}_{3}$ specifically bound to the $32-\mathrm{kD}$ protein to total counts added versus the picomoles of $\mathrm{BrAc}\left[{ }^{125} \mathrm{I}\right] \mathrm{T}_{3}$ bound per milligram of total protein as previously described (26). Extrapolation of this linear plot to the abscissa gave an estimate of the total enzyme present as $\mathrm{pmol} / \mathrm{mg}$ protein, assuming 1 mol of $\mathrm{BrAcT}_{3}$ is bound/mol enzyme. Quantifications were performed at least twice for each sonicate. Densitometric quantification of the 


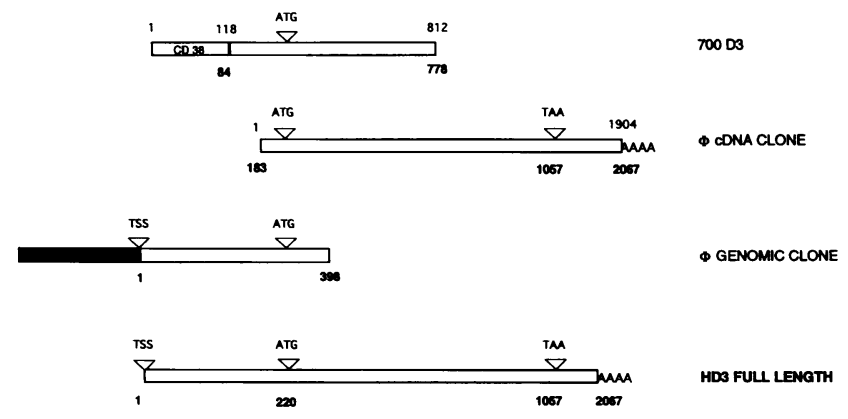

Figure 1. Human D3 clones. The numbers over the bars refer to the nucleotide sequence of the particular clone, whereas the bold numbers under each bar correspond to the nucleotide sequence of the predicted hD3 full length cDNA. The position of the transcriptional start site, (TSS), the translation initiation codon ( $A T G)$ and the stop codon (TAA) are also indicated. The white field areas correspond to cDNA sequences, the gray to genomic DNA.

autoradiographs was performed by a computing densitometer (Molecular Dynamics Inc., Sunnyvale, CA).

${ }^{75} \mathrm{Se}$ in vivo labeling. Plasmids were transfected by $\mathrm{CaPO}_{4}$ coprecipitation into the HeLa cell line, HtTA (21) cells, as previously described (30). $3 \mathrm{~d}$ before transfection, these cells were plated onto 60 -mm dishes in DME containing $10 \%$ FCS. $1 \mathrm{~d}$ before transfection the media was changed to DME containing $1 \%$ FCS supplemented with $100 \mathrm{pM} \mathrm{T}_{3}$, $10 \mathrm{mg} / \mathrm{ml}$ transferrin, $20 \mu \mathrm{g} / \mathrm{ml}$ insulin, and $50 \mathrm{nM}$ hydrocortisone to decrease the medium selenium concentrations. The day after transfection, the cells were shocked with $10 \%$ DMSO and fresh media containing $5 \mathrm{nM}$ unlabeled $\mathrm{Na}_{2} \mathrm{SeO}_{3}$ plus $6 \mu \mathrm{Ci} \mathrm{Na}{ }_{2}\left[{ }^{75} \mathrm{Se}\right] \mathrm{O}_{3} /$ dish. After $18 \mathrm{~h}$ of incubation, the cells were harvested, washed, resuspended in PE buffer, and sonicated. Aliquots of labeled cell sonicate were analyzed by SDSPAGE.

Sequence analysis. Nucleotide and protein sequence analysis was performed using the Sequence Analysis Software Package from the Genetics Computer Group (University Research Park, Madison, WI).

\section{Results}

Isolation of a human D3 cDNA. A combination of PCR and screening by homology was used to isolate a fragment $812 \mathrm{bp}$ long (700D3) from the CDM-8 library containing nucleotides 84-778 of the complete hD3 cDNA (Fig. 1). Since the first 5' $118 \mathrm{nt}$ of $700 \mathrm{D} 3$ was found to be $100 \%$ identical to the published sequence of the human lymphocyte antigen CD38 (Fig. 1), we suspected that this portion of the cDNA was a product of a cloning artifact. Since the $5^{\prime}$ ut region of XD3 extends only $24 \mathrm{nt}^{\prime}$ to the initiator ATG, the identity of the intervening nucleotides (between 119 and 195) in 700D3 was not clear. We next used the 700D3 5 ' clone to isolate 5 positive D3 clones from a $\lambda$-ZAP II library. These contained inserts varying in length from 1500 to 1905 nucleotides. The longest of these clones was subcloned into pBS and sequenced and contained nucleotides 195-2067 of the hD3 full-length cDNA. None of the phage inserts contained sequences 5 ' to nucleotide 195 (Fig. 2 ). To define the $5^{\prime}$ ut region of human D3 we next screened a human genomic library with a probe from the coding region. We identified several clones containing contiguous sequences identical to those in the 700D3 clone between the CD38 fragment and the $5^{\prime}$ border of the sequence homologous to the $5^{\prime}$ ut of XD3 (nt 84-200 of the final cDNA), establishing that these were contained within the human D3 gene.

We used the genomic fragment which extended $600 \mathrm{nt} 5^{\prime}$
1 AGCCCAAGATTTCTAGGGCATTGGCGCGCTGCTGGGTGACTTCCGGGCTCAAGTTGCAAG

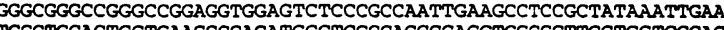

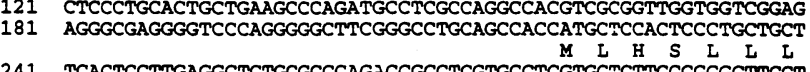

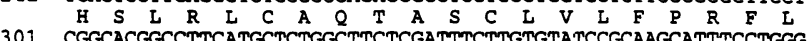
301 CGGCACGGCCTTCATGCTCTGGCTTCTCGATTTCTTGTGTATCCGCAAGCATTTCCTGGG 361 CCGCCGCCGCCGGGGCAAGCCCGAGCCCGAAGTGGAGCTCAACAGTGAAGGCGGGAGGT

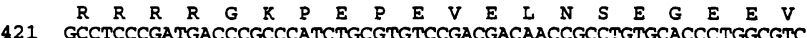
421 GCCTCCCGATGACCCGCCCATCTGCGTGTCCGACGACAACCGCCTGTGCACCCTGGCGTC 481

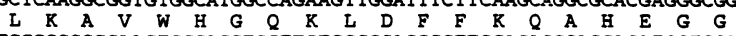

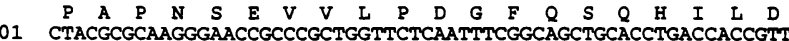

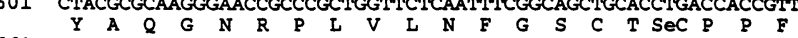
661 CATGGCGCGCATGAGCGCCTTCCAGCGCCTGGTCACTAAGTACCAGCGCGACGTCGACTT

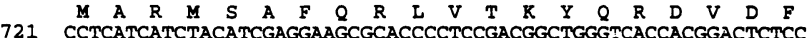
I I I Y I E E A H P S D G W V T T T 781 901 Q $G$ G A P G C A L V L L D T M A N S S S S S A 901 CTAGGCGCCTACTTCGAGCTCTCTATGTCATCAGAGTGGCACTATTATGTACCAGGG 961 CGGCCGTGGCCCCGACGGCTACCAGGTCTCTGAGCTGCGCACTTGGTTGGACGCTATGA 1021 TGAGCAACTGCACGGCGCTCGGCCCCGGAGGGTGTAAACATCCAACGGACAATTGACTGA E Q L H H G A R P R R V * 1201 CCCTCAGCCACATGAACAATCTCCCCTACCTCCTGGGACTCTGCTTCTGTAACTGTCTCA 1261 TTACACTGCTGGCTTGCCCTTGTCCGTGTGCCCCCAGGACTTTGCCTCTACAGCATTTTC 1321 TTACACCCCCTCCCCAGCGTGCCCTCAGCCAAGTGCTTTGGCCCGGTGCTTCCCGCAGCT 381 GCACAGAGACCTTGGCCACGCCCGCGCGCCCTGAGCGCAGCTGGGTTCCAGGAGACTCTC 441 AGCTCAGCTGAGCTAGTTGCCTGGCACCCACCTGTCGCGCGCGGAGAGGGGTTCCCTGT TGCTTTTGTGTCTGTTTCCTGTCCCTGGTAGGGGAAGTGATGTCGTGGATGGGGAGGGG GGGAGAGTAGTTTCCCCCGCTTGTTTTGGGTGCACAGGAGCCCCACTGCTGATGACGA CCTAAACCTTGAGGGGGAGGGTGCTCTGGGTTTCCGTGAGGTAACCACCTTAAATGGGAG 41 GGAAGTTGGGGTGTCTGCTTTGGGACCAGAGGAAGATAGCTTGAGAGGCATTGGCGGAGT 01 TCGCAGCGCCCAGGGAGAGAGAAAAAGCTGAGACTCCTGGGGATTGACGTTGGGGTGAT GGAGTCCGGGGAAAGAGAGGTGGGGGAGAGCCTGAGGTCCCCAAGTGAGGGGAGTCCTR 1 GGCAGAGCTGCTGATTGTGGGGTGGGAGGTGGAGGGCCCCTGATTCGAAGGCCATTTGG 1 TGAGTGTTTTGCTGGAAATATTTCCTGTATATAAACTTCTTTCAATCTACAATAATAAAG 1041 TCTTGGGTAAACTCCAAAAAAGGAA

Figure 2. cDNA and predicted amino acid sequence of the human D3. The amino acid selenocysteine is noted as $\mathrm{SeC}$.

to the initiator ATG to map the transcriptional start site using $\mathrm{S} 1$ nuclease and human placental poly $\left(\mathrm{A}^{+}\right)$mRNA. There was one major protected band of $\sim 187$ bp ending with the $\mathrm{A}$ or $\mathrm{C}$ nucleotide $220 / 221$ bp $5^{\prime}$ to the translation initiation codon (data not shown).

The hD3 cDNA contains 220 bp of $5^{\prime}$ untranslated region, an 834-bp open reading frame which contains an in frame TGA codon at position $650-652$, and a $3^{\prime}$ untranslated region of $1,012 \mathrm{bp}$. The open reading frame begins with an ATG codon after a Kozak consensus sequence (CCACC, Fig. 2) and ends with a TAA codon at position 1056. A consensus polyadenylation signal (AATAAA) is present at position 2034-9 (Fig. 2) and is followed by a short poly A tail. The deduced amino acid sequence predicts a protein of 278 residues, with a molecular mass of $31.5 \mathrm{kD}$ assuming the TGA codon at position $650-652$ encodes selenocysteine. HD3 is highly homologous to the XD3 enzyme, $66 \%$ identity at the nucleotide level and $58 \%$ identity (73\% similarity) to the XD3 deduced amino acid sequence. The human enzyme contains a 12 -amino acid insert in the amino-terminal region and is seven residues longer than XD3 (Fig. $3 \mathrm{~A}$ ). There is also a potential $\mathrm{N}$-glycosylation site (NXS) in the predicted sequence at residues 222-224 which is conserved in XD3. An hydropathy analysis (Fig. $3 B$ ) revealed a hydrophobic amino-terminal portion consistent with a transmembrane domain.

Northern blotting. A ${ }^{32} \mathrm{P}$-labeled $\mathrm{hD} 3$ full-length cDNA hybridizes to a single mRNA species of $\sim 2.1-2.2 \mathrm{~kb}$ in human placenta (Fig. $4 \mathrm{~A}$ ) consistent with the size of the composite cDNA. No hybridizing band could be detected in RNA from seven other human tissues. A low intensity band of the same 
Human D3 1 MLHSLLLHSLRLCAQTASCLVLFPRFLGTAPMINLLDFICIRKHFLGRRR 50 ||$|: \quad| .:|| ..|| ..|:|:||||||::|||||||||||::$.

Xeno D3 1 MLHCAGPFTGKLVKQVAACCIULPRFLITEIMLNLLDFOCIRRRVLITAR 50

51 RGRPEPEVEI NSEGEEVPPDDPPICVSDONRICTI ASLKAVWHACRKDFF 100 $|: \ldots \ldots:|||:|||| \cdot||:||::||:||||||||||: \mid$ $51 \ldots \ldots \ldots \ldots$. EESTAEHEDPPICVSDSNRMCTVESLRAVWHGQKLDYF 88

101 RQAFEGGPAPNSEVLIPDGFOSOFIIDYAOGNRPLVINFGSCT*PPFMAR 150 ||||$. .||||||:.: \mid$. . . ||$|:|.||||.|:|||||||||||||$ 89 KSAFLOCSAPNIEVMLDGRRLCKIIDFSQGKRPLVNNFGSCT*PPFMAR 138

151 MSAFORLVIKYORDVDFLITYIEEAHPSDCWUTTDSPYIIPQHRSLEDRV 200 $:|:|.|\ldots \quad|||:.:||||||||||||:|| \ldots|||||| .:|:| \mid:$ 139 LOAYRRLAAOFVGIADFLLVYIEEAHPSDGWLSTDASYQIPQHOCIODRL 188

201 SAARVLOQGAPGCALVIDTMANSSSSAYGAYYERLYVIQSGTIMYQOGRG 250

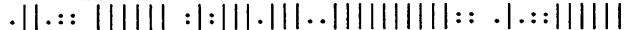
189 AAAQIMLOGAPGCRVVVDMINSSNAAYGAYFERLYIVLEGKVYYQGGRG 238

251 PDGYOVSEIRTWLFRYDEDIHGARPRRV...... 278

$|:||.:|||||||||:.: .|| \mid:: .$.

239 PEGKKLSEL RMMLIDOYQOCH MGIKGSOQWIQV 271

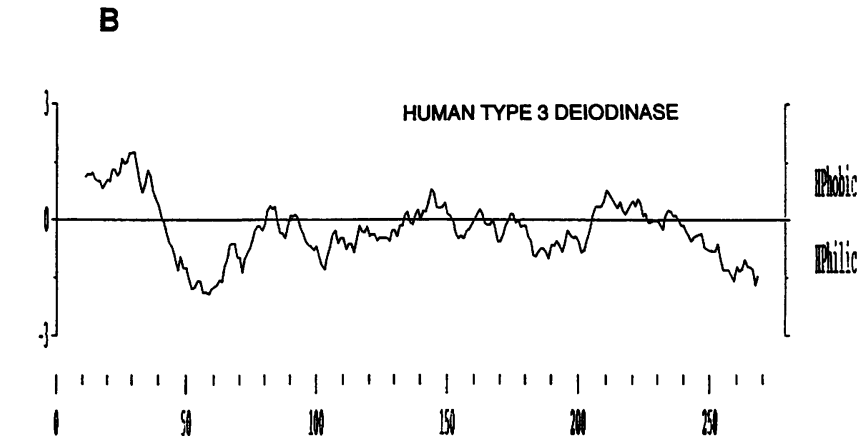

Figure 3. (A) Alignment of the predicted amino acid sequences of human and Xenopus laevis D3 proteins. Selenocysteine at position 144 is shown with an asterisk. $(B)$ Hydropathy analyses of human D3 protein using the Kyte-Doolittle algorithm (window $=21$ ) as predicted by the PEPPLOT program of University of Wisconsin Genomic Computer Group.

size appeared in lung poly $(\mathrm{A})^{+}$with $5 \mathrm{~d}$ longer exposure but not in brain. This pattern of distribution correlates with previous demonstrations of D3 activity in human placenta, but does not show expression of D3 in human brain which would be expected

A
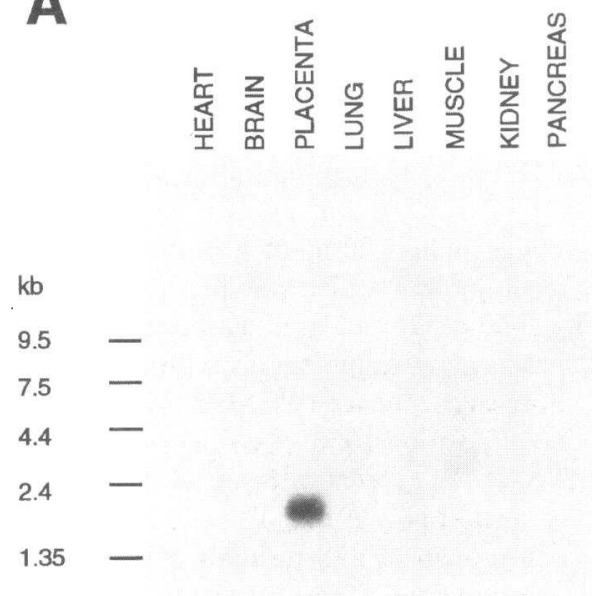

B

$\beta$-ACTIN

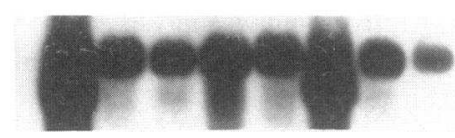

Figure 4. Northern blot analysis of human type 3 deiodinase. The blot was probed with an $\mathrm{hD} 3(A)$ or a mouse $\beta$-actin cDNA $(B)$. Each lane contains $2 \mu \mathrm{g}$ of human Poly $(\mathrm{A})^{+}$RNA. The sizes of the molecular weight markers are indicated. on the basis of animal studies (6). Probing with a mouse $\beta$ actin fragment (Fig. $4 \mathrm{~B}$ ) confirmed the presence of adequate quantities of well preserved mRNA in all lanes.

Affinity labeling of $h D 3$. Bromoacetyl $\left[{ }^{125} \mathrm{I}\right] \mathrm{T}_{3}$ labeling of the hD3 transfected HEK-293 cell sonicates was performed to establish if transiently expressed D3 could be specifically labeled with $\mathrm{BrAc}\left[{ }^{125} \mathrm{I}\right] \mathrm{T}_{3}$ and, if so, to determine the size and quantity of the transiently expressed protein. When $\mathrm{hD} 3 \mathrm{cDNA}$ is transfected, a band of $\sim 32 \mathrm{kD}$ appears, which is not present in the vector-transfected cells (Fig. 5). The $\mathrm{BrAc}\left[{ }^{125} \mathrm{I}\right] \mathrm{T}_{3}$ labeling of the $\mathrm{hD} 3$ protein is specifically blocked by increasing concentrations of cold $\mathrm{BrAcT}_{3}$ (Fig. 5) and a plot of specifically

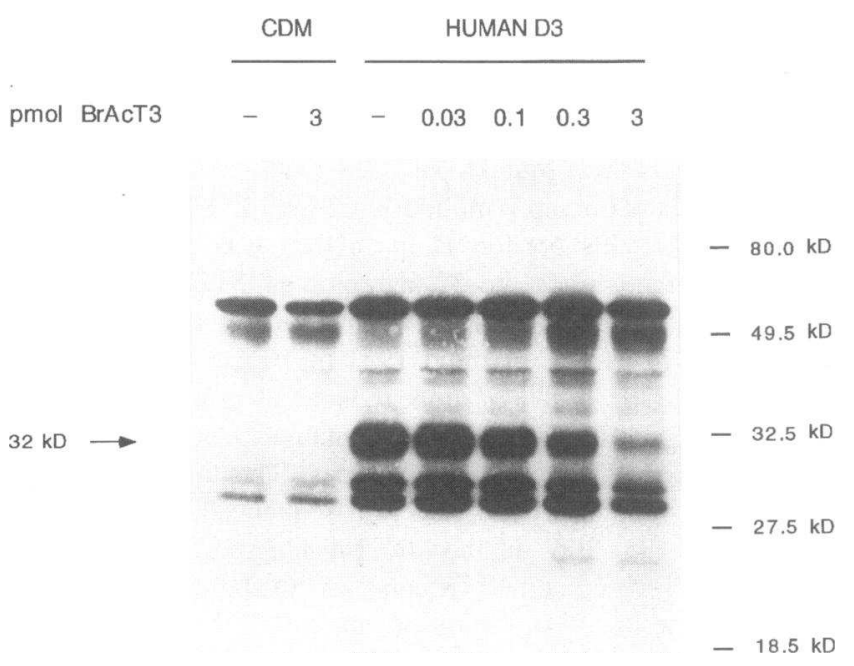

Figure 5. $\mathrm{BrAcT}_{3}$ labeling of transiently expressed human type 3 deiodeinase. Transfection of the CDM-8 vector alone or vector containing the human D3 as indicated. Cell sonicate protein $(100 \mu \mathrm{g})$ was incubated with a constant quantity of $\mathrm{BrAc}\left[{ }^{125} \mathrm{I}\right] \mathrm{T}_{3}$ together with increasing amounts of added unlabeled $\mathrm{BrAcT}_{3}$ as indicated above each lane. The positions of the molecular weight standards are shown. 


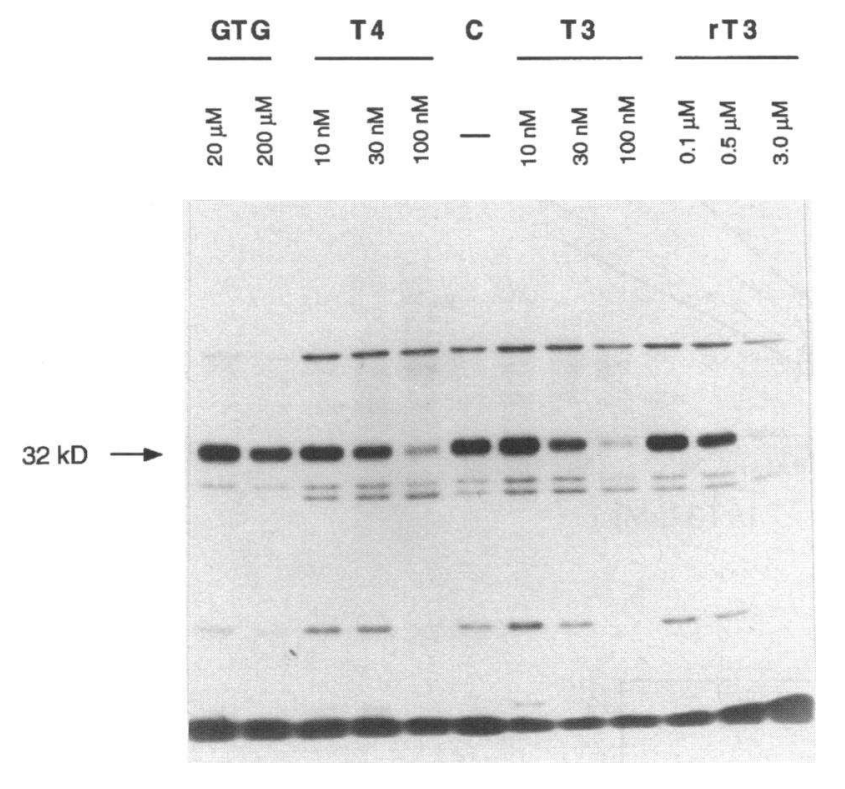

labeled protein vs $\left[\mathrm{BrAcT}_{3}\right]$ is linear allowing quantitation of the transiently expressed $\mathrm{hD} 3$. These results indicate that the hD3 cDNA encodes a protein of the size predicted from the open reading frame if the stop function of the UGA codon at position 650 is suppressed and the UAA at 1055-7 is the true stop codon (Fig. 2).

We have previously shown that covalent labeling of in vitro expressed $\mathrm{D} 1$ by $\mathrm{BrAc}\left[{ }^{125} \mathrm{I}\right] \mathrm{T}_{3}$ is blocked by substrates or competitive inhibitors of the deiodinase due to occupancy of the selenocysteine-containing active site. Similarly, $\operatorname{BrAc}\left[{ }^{125} I\right] \mathrm{T}_{3}$ labeling of the $32-\mathrm{kD}$ protein is blocked in a dose-dependent fashion by D3 substrates (Fig. 6). The estimated order of potency of these compounds to block $\mathrm{BrAcT}_{3}$ labeling mirrors that expected from the substrate specificities of the human or rat placental enzyme, with $\mathrm{T}_{3}>\mathrm{T}_{4}>>\mathrm{rT}_{3}$ (Fig. $6 \mathrm{~A}$ ) (6-8). Also 3,5-diiodothyronine $\left(3,5,-\mathrm{T}_{2}\right)$ and 3,3' $\mathrm{T}_{2}$ (Fig. $6 \mathrm{~B}$ ) inhibit the $\mathrm{BrAc}\left[{ }^{125} \mathrm{I}\right] \mathrm{T}_{3}$ incorporation into the $32-\mathrm{kD}$ protein at concentrations comparable to those of $\mathrm{T}_{3}$ or $\mathrm{T}_{4}$. Gold-thioglucose (GTG), a potent inhibitor of D1 action and $\operatorname{BrAc}\left[{ }^{125} \mathrm{I}\right] \mathrm{T}_{3}$ labeling $\left(K_{\mathrm{i}} \sim 10 \mathrm{nM}\right)(31)$, is much less efficient as an inhibi-

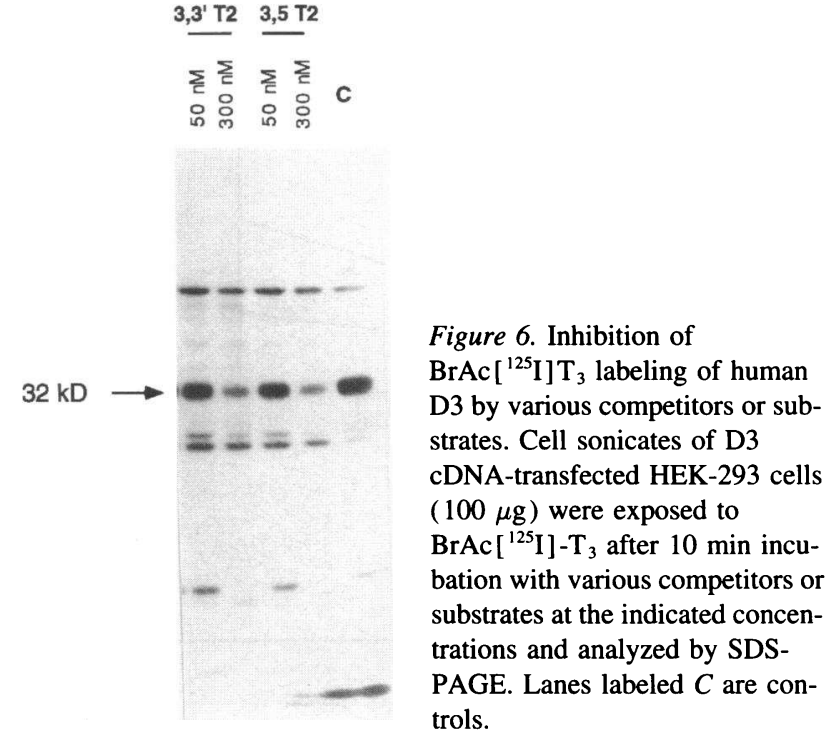

tor of $\mathrm{BrAc}\left[{ }^{125} \mathrm{I}\right] \mathrm{T}_{3} \mathrm{D} 3$ labeling. As deduced from labeling reactions in the presence of GTG (Fig. $6 \mathrm{~A}$ ), 2 mM GTG would be required for a $50 \%$ reduction of the $\mathrm{BrAc}\left[{ }^{125} \mathrm{I}\right] \mathrm{T}_{3}$ binding.

Human D3 catalyzes both 5 and 5' iodothyronine deiodination. To analyze the reaction kinetics of $\mathrm{hD} 3$, we transiently expressed the protein in HEK-293 cells which contain no endogenous D3. Cell homogenates from hD3-transfected cells deiodinate the inner ring of $\mathrm{T}_{3}$ in a saturable fashion, producing ${ }^{125} \mathrm{I}$ and 3,3' diiodothyronine. The apparent $K_{\mathrm{m}}$ of the $\mathrm{hD} 3$ enzyme for $\mathrm{T}_{3}$ is $1.2 \mathrm{nM}$ and the $V_{\max }$ is $4.0 \mathrm{U}\left(1 \mathrm{U}=1 \mathrm{pmol} \mathrm{T}_{3}\right.$ deiodinated $\mathrm{min}^{-1} \mathrm{mg}^{-1}$ sonicate protein (Table I). The enzyme requires DTT as cofactor in the deiodination reaction, with maximal 5D activity observed at $10 \mathrm{mM}$ DTT (Fig. $7 \mathrm{~B}$ ). GTG is a competitive inhibitor of $\mathrm{T}_{3} 5$ deiodination, with an apparent $K_{\mathrm{i}}$ of $5.2 \mu \mathrm{M}$ (Fig. $7 \mathrm{~A}$ ). The enzyme is insensitive to $6 n$ propylthiouracil (PTU) inhibition, with no effect observed up to concentrations of $1 \mathrm{mM}$ at varying DTT levels (Fig. $7 \mathrm{~B}$ ). Shown in Table $I$ are the values for $[E]$, the picomoles of specifically bound $\mathrm{BrAcT}_{3} / \mathrm{mg}$ HEK-293 cell sonicate protein in the preparation used for kinetic analyses. Using these results,

Table 1. Kinetics of 5 and 5' Deiodination by Transiently Expressed hD3

\begin{tabular}{|c|c|c|c|c|c|c|c|}
\hline $\begin{array}{l}\text { Deiodination activity and } \\
\text { substrate }\end{array}$ & EXP & $K_{\mathrm{m}}$ & $V_{\max }$ & {$[\mathrm{E}]^{*}$} & $K_{\text {cat }}$ & $K_{\text {cal }} / K_{\mathrm{m}}$ & $K_{\mathrm{i}}$ GTG \\
\hline & & $\mu M$ & pmol/min mg prot & pmol mg prot ${ }^{-1}$ & $\min ^{-1}$ & $\min ^{-1} \mu M^{-1}$ & $\mu M$ \\
\hline \multirow[t]{3}{*}{5 deiodinase $\left(\mathrm{T}_{3}\right)$} & 1 & 0.0011 & 3.96 & 0.140 & 28.2 & 25636 & 6.4 \\
\hline & 2 & 0.0013 & 4.08 & 0.215 & 19.0 & 14615 & 4.1 \\
\hline & mean & 0.0012 & 4.02 & 0.177 & 23.6 & 19666 & 5.2 \\
\hline \multirow[t]{3}{*}{$5^{\prime}$ deiodinase (reverse $T_{3}$ ) } & 3 & 0.333 & 0.24 & 0.215 & 1.1 & 3.3 & 0.9 \\
\hline & 4 & 0.337 & 0.21 & 0.140 & 1.5 & 4.4 & - \\
\hline & mean & 0.335 & 0.23 & 0.177 & 1.3 & 3.8 & \\
\hline
\end{tabular}

Exp, experiment; prot, protein; * Enzyme quantification was performed by saturation analysis using $\left.\mathrm{BrAc}^{125} \mathrm{I}\right] \mathrm{T}_{3}$ as described in Methods. 
A

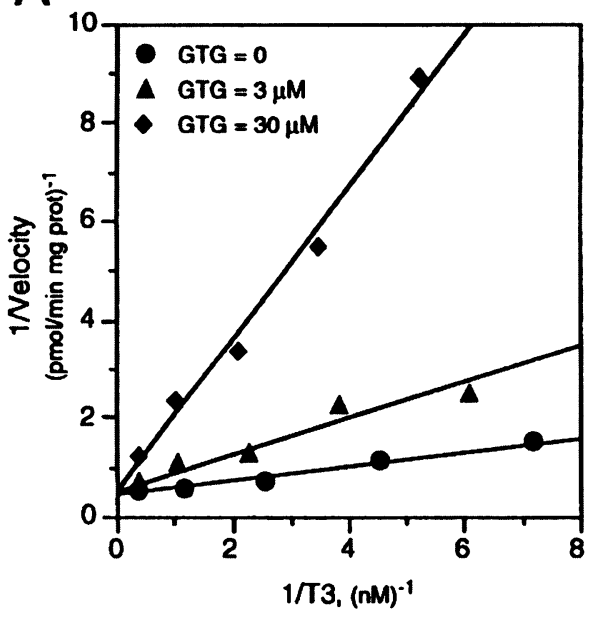

C

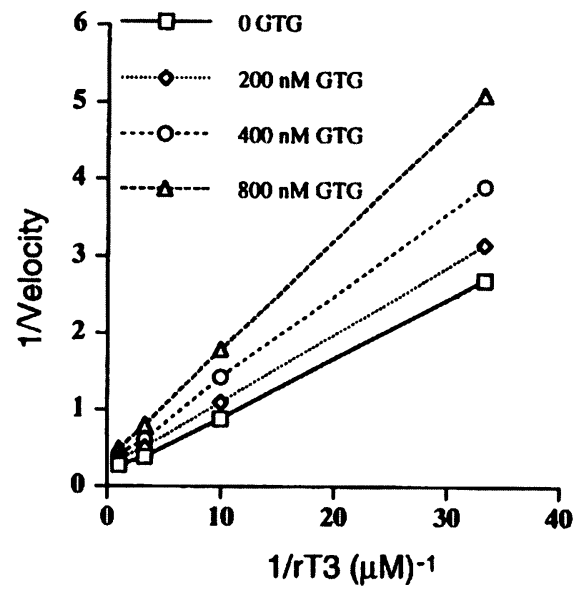

B

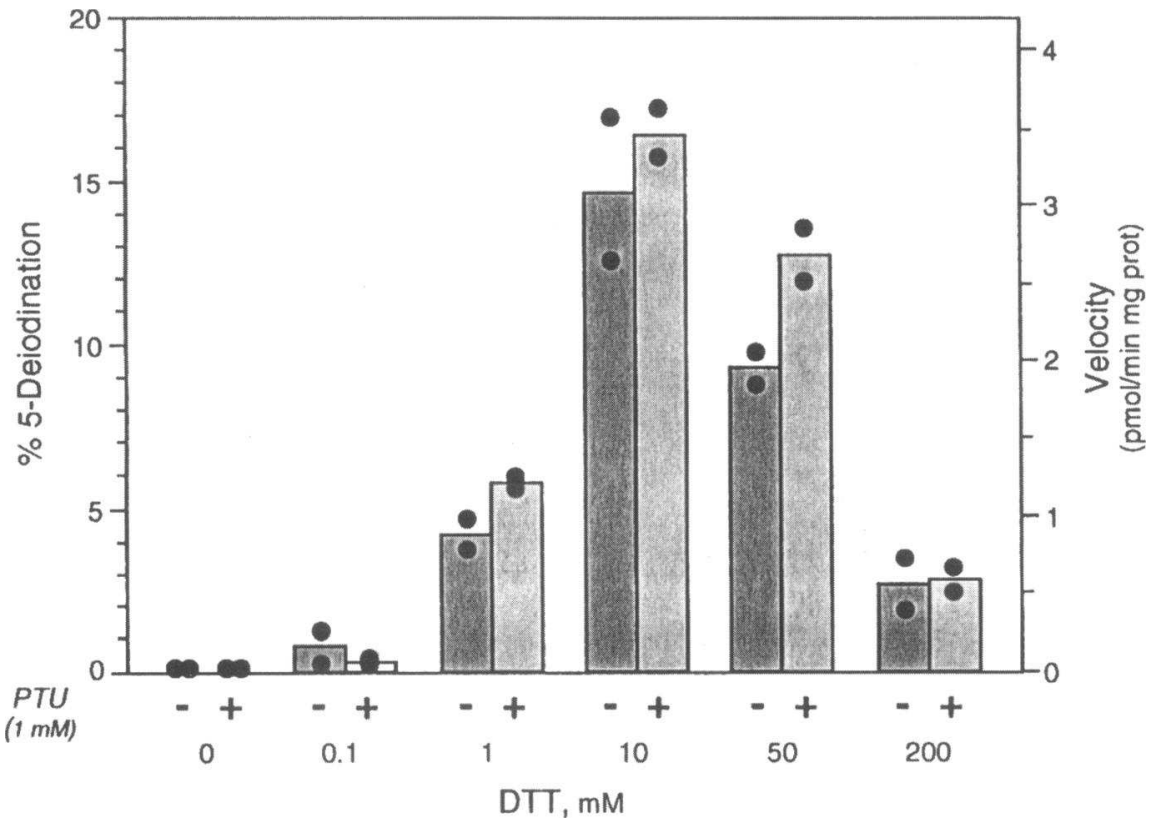

Figure 7. Kinetic studies of 5 deiodination of $\mathrm{T}_{3}(A$ and $B)$ or $5^{\prime}$ deiodination of reverse $\mathrm{T}_{3}(C)$ by transiently expressed human D3. $(A)$ Inhibition by GTG. $(B)$ Effect of incubations with various concentrations of DTT with or without PTU. Dots indicate results of independent kinetic assays and the height of the bars their mean. Activities are expressed either as percent deiodination or as velocity. (C) Effect of GTG on 5' deiodination of reverse $\mathrm{T}_{3}$. The Velocity is in the same units as in $A$. Results are representative of two closely agreeing experiments. the $K_{\text {cat }}$ for 5 deiodination of $\mathrm{T}_{3}$ was 23 molecules $\min ^{-1}$ and the $K_{\text {cat }} / K_{\mathrm{m}}$ ratio for $\mathrm{T}_{3} 5$ deiodination is $19,660 \mathrm{~min}^{-1} \mu \mathrm{M}^{-1}$ (Table I).

Type 3 deiodinase also catalyzes $5^{\prime}$ deiodination of reverse $\mathrm{T}_{3}$, although with much lower efficiency. For reverse $\mathrm{T}_{3}$ to $3,3^{\prime}$ $\mathrm{T}_{2}$ conversion, the $K_{\mathrm{m}}$ was $0.33 \mu \mathrm{M}$ and the $V_{\max }$ is $0.24 \mathrm{U}$ (Table. I). The $K_{\text {cat }}$ for $5^{\prime}$ deiodination of $\mathrm{rT}_{3}$ is 1.4 molecules $\min ^{-1}$, about 10 -fold lower than that for the 5 deiodination of $\mathrm{T}_{3}$ with the $K_{\text {cat }} / K_{\mathrm{m}}$ ratio of $3.8 \mathrm{~min}^{-1} \mathrm{mM}^{-1}$ markedly lower than that for 5 deiodination (Table I). GTG also inhibits $5^{\prime}$ deiodination of reverse $\mathrm{T}_{3}$, with an apparent $K_{\mathrm{i}}$ of $0.9 \mu \mathrm{M}$ (Fig. $7 C$ ). This reaction was also insensitive to PTU inhibition at concentrations up to $1 \mathrm{mM}$.

Labeling of $h D 3, X D 3$, and $r D 1$ with ${ }^{75} S e$. To establish that the transiently expressed $\mathrm{hD} 3$ incorporates selenium, HtTA cells were transfected with the hD3 cDNA and incubated with $\mathrm{Na}_{2}\left[{ }^{75} \mathrm{Se}\right] \mathrm{O}_{3}$ for $18 \mathrm{~h}$. The hD3 cDNA encodes an $\sim 32-\mathrm{kD}$ ${ }^{75} \mathrm{Se}$-labeled protein and its ${ }^{75} \mathrm{Se}$-labeling is enhanced 10 -fold by cotransfection with the human selenophosphate synthetase cDNA, SelD (Fig. 8). In the same experiment, we also could identify the ${ }^{75} \mathrm{Se}$-labeled rat D1 protein, which appears as a radiolabeled $29-\mathrm{kD}$ band in the $\mathrm{rD} 1 \mathrm{cDNA}$ transfected cells (Fig. 8). With a threefold longer exposure time, a $\sim 30-\mathrm{kD}$ band could be seen in XD3 cDNA transfected cells indicating that the rate of synthesis or the efficiency of selenocysteine incorporation into the Xenopus enzyme is much lower than that of $\mathrm{hD} 3$.

The hD3 mRNA contains a SECIS element. We have previously shown that eukaryotic selenoprotein mRNAs contain SECIS elements in the $3^{\prime}$ ut region which are necessary and sufficient for selenocysteine incorporation at UGA codons ( 18 , 32 ). Transfection of a cDNA in which the $3^{\prime}$ ut region $\left(3^{\prime}\right.$ to nt 1118) is deleted did not produce a functional deiodinase indicating the presence of SECIS activity in the $3^{\prime}$ ut of $\mathrm{hD} 3$ (Fig. 9). To confirm this and to compare the potency of the hD3 SECIS element with that of the rat D1 mRNA, we inserted 


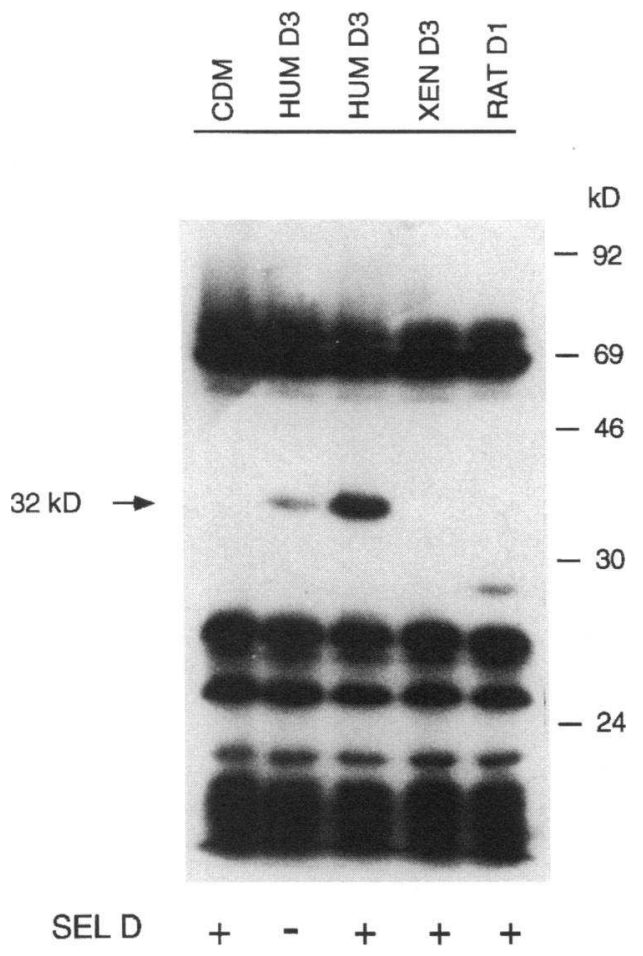

Figure 8. Incorporation of ${ }^{75} \mathrm{Se}$ into transiently expressed human or Xenopus D3 or rat D1 in the presence or absence of coexpressed human SelD in HtTA cells. Cells were incubated in selenium-depleted medium for $1 \mathrm{~d}$ before transfection of plasmids expressing the various proteins. CDM indicates cells transfected with the vector alone.

the hD3 $3^{\prime}$ ut region (nt 1118-1720) downstream of the rat D1 cDNA coding region. In the absence of an intact SECIS element, this construct does not express a functional D1 (Fig. 9 ). The deiodinase activity of the D1-hD3(SECIS) construct was $\sim 4.5$-fold higher than that of the wild-type D1 cDNA, similar to that of the previously characterized D1-selenoprotein $P$ (SECIS) construct (32). These results indicate there is a highly potent SECIS element in $3^{\prime}$ ut region of the $\mathrm{hD} 3 \mathrm{mRNA}$.

Analysis by a folding program was used to determine if the inserted SECIS sequence would be predicted to form a stemloop structure, similar to that of the D1 SECIS element. Five potential stem loops were predicted by this program, but the segment between nt 1480 and 1720 (Fig. $10 \mathrm{~A}$ ), had the highest negative free energy $(-44.5 \mathrm{kcal})$. To localize the SECIS activity more precisely we prepared a construct in which these sequences were inserted 3 ' to the D1 coding region. This sequence is able to drive D1 expression with an efficiency about $50 \%$ of the parent D1-D3(SECIS) construct (Fig. 9). Thus, while this mRNA segment still has twice the activity of the D1 element, additional sequences $5^{\prime}$ to 1480 are necessary for the full hD3 SECIS potency.

\section{Discussion}

Human D3 is closely related to Xenopus D3 and human D1. Type 3 deiodinase catalyzes the conversion of $T_{4}$ to reverse $T_{3}$ and $T_{3}$ to $3,3^{\prime}-T_{2}$, both metabolically inactive products. The $D 3$ enzyme thus shares with D1 the capacity to inactivate thyroid hormone though D3 does not accept sulfated iodothyronines which are highly preferred for inner-ring deiodination by D1 (33). The catalytic constants for 5 deiodination of $\mathrm{T}_{3}$ and $5^{\prime}$

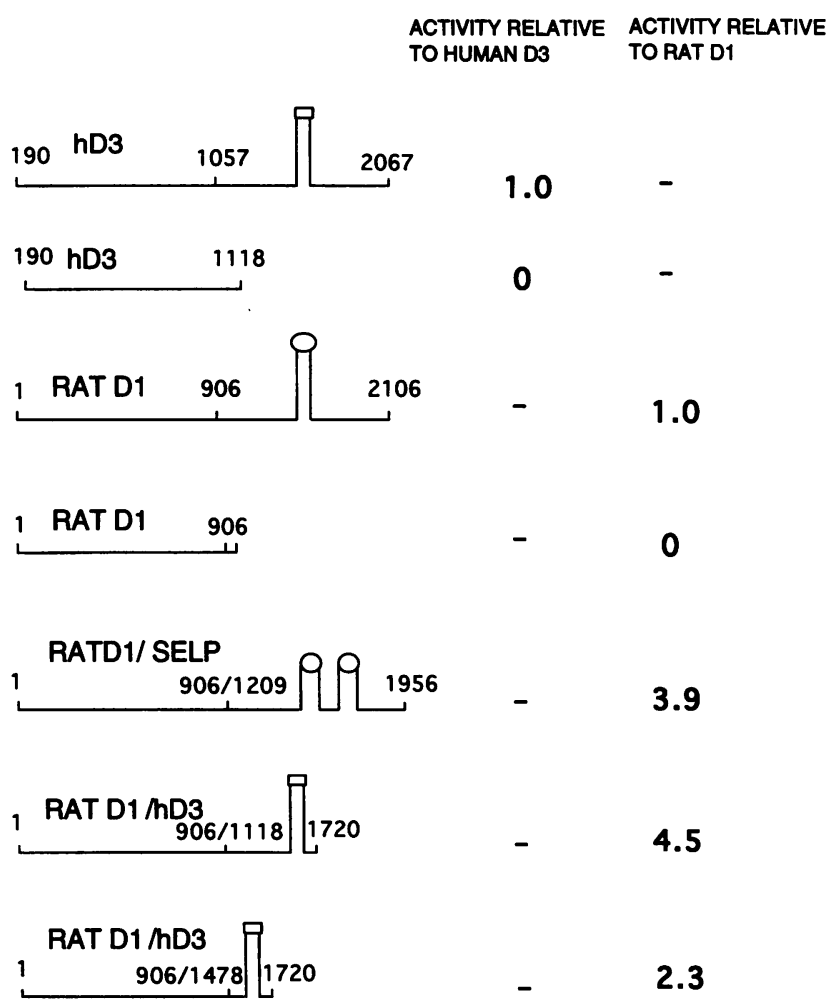

Figure 9. Analyses of the functional potency of the human D3 SECIS element. HEK-293 cells were transfected as described in Methods with CDM-8 expression plasmids containing the constructs schematically presented. Cell sonicates were prepared $48 \mathrm{~h}$ after transfection and were assayed for $5^{\prime}$ deiodinase activity using reverse $T_{3}$ as substrate. Transfections were performed in the same experiment for each series of constructs. Deiodinase activities were normalized for transfection efficiency by assay of hGH expressed from a cotransfected TKGH plasmid and results expressed as a multiple of the activity of the parent construct (hD3 or $\mathrm{rD1}$ ) in the same transfection. Results are the mean of three closely agreeing experiments.

deiodination of reverse $T_{3}$ are virtually identical to those for XD3 (17) and to those found for rat tissues (8). While the enzyme catalyzes outer ring deiodination of reverse $\mathrm{T}_{3}$ as does $\mathrm{D} 1$, the $K_{\text {cat }} / K_{\mathrm{m}}$ ratio is nearly four orders of magnitude lower than for inner ring deiodination of $\mathrm{T}_{3}$ indicating that the latter is a much more efficient reaction. Despite this efficiency, the $K_{\text {cat }}$ for inner ring deiodination of $\mathrm{T}_{3}$ by D3 is 24,100 -fold lower than that for $5^{\prime}$ deiodination of reverse $\mathrm{T}_{3}$ by D1 (26). This may explain why D3 deiodination is insensitive to PTU since it seems likely from studies of both wild-type and sitedirected D1 mutants that an intermediate Se-I complex must be formed for interaction with this agent $(8,12,34)$.

Human D3, like the Xenopus enzyme and D1, is a selenocysteine-containing protein as evidenced by the presence of an in frame UGA codon, a requirement for an SECIS element for successful translation, and the fact that it incorporates ${ }^{75} \mathrm{Se}$ in a SeID-dependent fashion. The deduced amino acid sequences of the human and Xenopus enzyme are 58\% identical (73\% similar). In addition, there is $47 \%$ similarity with the bifunctional ( $5^{\prime}$ or 5 deiodination) human D1 enzyme which is especially high in the region surrounding the selenocysteine residue (11).

Type 3 deiodinase is an integral membrane protein resistant 


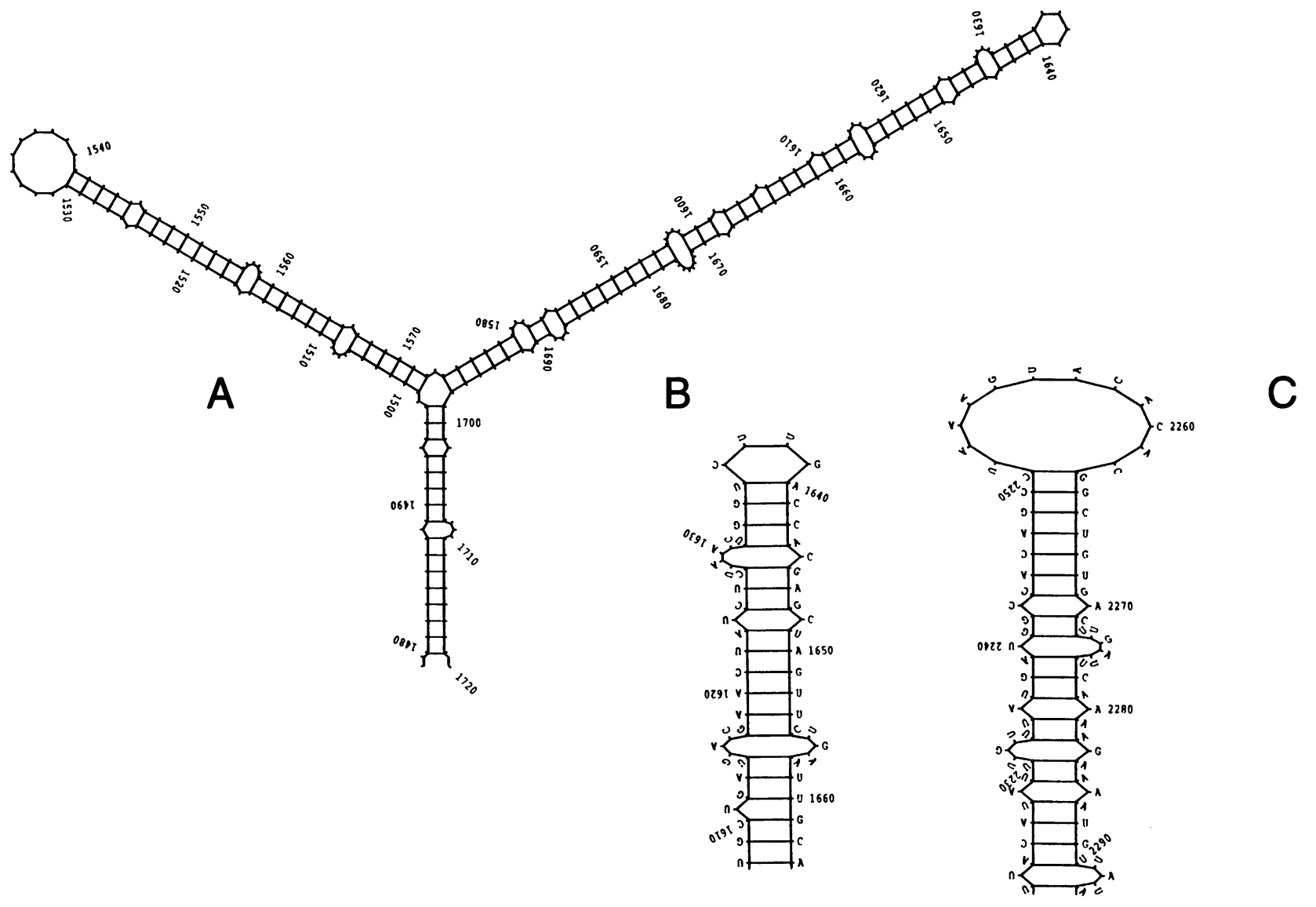

Figure 10. Predicted structures of portions of the $3^{\prime}$ ut mRNA of the human D3 ( $A$ and $B$ ) and D1 $(C)$ mRNAs. The sequence shown in $A$ (nt 1480-1720) has 2.4-fold the SECIS activity of the wild type D1 SECIS element. An enlargement of the terminal portion of the hD3 major stem loop is shown in $B$ for comparison with the human D1 stem loop shown in $C$. Structural analyses were performed using the FOLD program of the University of Wisconsin Genetics Computer Group Software.

to extraction from microsomal membranes by high $\mathrm{pH}$ (35). Hydropathy analysis of the predicted protein revealed a highly hydrophobic amino terminal region of about 40 amino acids which is the only portion of the protein which can qualify as a membrane spanning domain (Fig. $3 \mathrm{~B}$ ). The amino-terminal location of this sequence is similar to that found for the D1 enzyme (36).

The most significant difference between $\mathrm{hD} 3$ and XD3 is the presence of a 12 amino acid insertion at position 51 in the human protein. The location of this insert, just carboxy-terminal to the hydrophobic domain, suggests that it would be found immediately external to the lipid bilayer. If the topology of D3 is similar to that of D1, this would be located in the cytoplasmic compartment (36). It is a hydrophilic sequence with a number of charged amino acids but its presence does not alter the kinetic characteristics of the human D3 enzyme for either $T_{3}$ or reverse $\mathrm{T}_{3}$ relative to that of XD3 (17).

Human D3 mRNA is expressed in placenta and lung. Northern blotting identified a $2.1-2.2-\mathrm{kb}$ transcript in placenta and lung but not in brain. The absence of the expected positive signal in the brain mRNA sample could be explained either by very low mRNA levels in this tissue or by a poor representation of D3 expressing portions of the CNS in the sample examined. In addition, D3 activity is much higher in fetal than in adult rat brain (37), and we are aware of only one study demonstrating D3 activity in normal adult human brain (38). D3 activity has been identified in human CNS malignancies (39), and more extensive studies will be required before this issue can be resolved.

Human D3 can be affinity labeled in vitro by $\mathrm{BrAcT}_{3}$. Previous studies have shown that $\mathrm{BrAcT}_{3}$ is an excellent affinity label for the D1 enzyme $(29,31,40)$. On the other hand, similar techniques were unsuccessful in achieving specific labeling of D3 in rat brain microsomes (35) though partial success was obtained with rat placental microsomes (15). Schoenmakers et al. interpreted the 32-kD band found after $\mathrm{BrAcT}_{3}$ labeling in microsomes of various tissues as being nonspecific since it was present in a number of tissues which did not express D3 activity and was not blocked by incubation with substrate (35). Based on comparisons of $V_{\max }$ estimates, the sonicate from transiently transfected HEK-293 cells has 30-40 times the specific D3 activity of rat brain microsomes explaining the specificity of the labeling we observed (Figs. 5 and 6). Santini et al. also labeled a $32-\mathrm{kD}$ protein in rat placental microsomes but only $\sim 50 \%$ of $\mathrm{BrAcT}_{3}$ incorporation could be blocked by incubation with $150 \mu \mathrm{M} \mathrm{T} \mathrm{T}_{3}$. As shown in Fig. 6, a $\mathrm{T}_{3}$ concentration of $100 \mathrm{nM}$ is sufficient to block completely $\mathrm{BrAcT}_{3}$ labeling of D3. Thus, even in placental microsomes, a maximum of $50 \%$ of the $32-\mathrm{kD} \mathrm{BrAcT}$ labeled protein is $\mathrm{D} 3$. The identities of the other $\mathrm{BrAcT}_{3}$ labeled $32-\mathrm{kD}$ protein $(\mathrm{s})$ in placenta, brain, and other tissues are not known.

There is a striking difference between the concentration of 
GTG required for inhibition of D3 activity (1 or $5 \mu \mathrm{M})$ and that for blocking $\mathrm{BrAcT}_{3}$ labeling $(\sim 2 \mathrm{mM})$. This is in contrast to results with D1 where the $K_{\mathrm{i}}$ for GTG is $\sim 10 \mathrm{nM}$ and 100 nM GTG blocks labeling completely $(11,41)$. It suggests that the access of $\mathrm{BrAcT}_{3}$ to the binding site of D3 is markedly favored over that of GTG. Similarly, GTG is an extremely effective inhibitor of type 1 deiodinase activity, whereas 1,000 fold higher concentrations are required to inhibit D3. Thus, while GTG is a competitive inhibitor (Fig. 7), the conformation of the substrate binding site is not favorable to the entry of this compound.

Synthesis of ${ }^{75}$ Se-labeled $h D 3, X D 3$, and rD1. The transiently expressed human D3, Xenopus D3, and rat D1 can be labeled with ${ }^{75} \mathrm{Se}$ in cell culture. The results in Fig. 8 illustrate that while this occurs under standard conditions in seleniumdepleted media, ${ }^{75} \mathrm{Se}$ incorporation is markedly enhanced by coexpression of the human selenophosphate synthetase ( $h$ SelD). This enzyme catalyzes the formation of selenophosphate, the active selenium donor in the eukaryotic selenocysteine incorporation process $(23,42)$. The quantity of ${ }^{75} \mathrm{Se}-\mathrm{la}$ beled $\mathrm{hD} 3$ formed is much greater than that of rat $\mathrm{D} 1$ consistent with the presence of a strong SECIS element in the $3^{\prime}$ ut of the hD3 mRNA (Fig. 9).

Recent studies have shown that rat placental D3 activity is not reduced by dietary selenium deficiency as is hepatic D1, leading to the speculation that placental D3 is not a selenoprotein (16). Since this is unlikely, other explanations for the lack of effect of selenium deficiency on placental D3 activity must be sought. These include either that the placenta, like the brain and thyroid $(43,44)$, is resistant to selenium depletion or that selenium incorporation into D3 has a high priority over other pathways of cellular selenocysteine incorporation.

Human D3 contains highly potent SECIS element. Deletion studies confirmed that a SECIS element is located in the 3' ut region of hD3 cDNA. Studies with chimeric D1/D3 3' ut constructs showed that this sequence is sufficient for the incorporation of Se into a heterologous (D1) selenoenzyme (Fig. 9). We have previously shown that the SECIS element of rat selenoprotein P mRNA consists of two adjacent stem loops and has four times the potency of that in D1 mRNA (32). The potency of the hD3 SECIS element was comparable to this, suggesting a high priority for selenocysteine incorporation into D3 as well. A portion of this sequence, nt 1478-1720, was less active than the entire $3^{\prime}$ ut but still had over twofold the potency of the rat D1 SECIS. This mRNA sequence is predicted to form two stem-loops (Fig. $10 \mathrm{~A}$ ) though it shares low identity with both the Xenopus $3^{\prime}$ ut sequence $(39 \%)$ and the D1 SECIS element $(33 \%)$. The longer of these (Fig. $10 \mathrm{~B}$ ) contains two nucleotide sequences conserved in the SECIS elements of D1, GPX, and selenoprotein P (loops 1 and 2) (32). These are YNATGANGR (nt 1611-1619) in the ascending limb of the stem and the unpaired YUGR (nt 1654-1657) on the descending limb (compare Fig. 10, $B$ and $C$ ). However, the predicted loop does not contain the A residues which are also conserved in previously analyzed SECIS structures (32). Understanding the mechanism by which functional SECIS potency is preserved without this characteristic feature will require further dissection of this structure.

Taken together, these results show that there is a major similarity between the human D3 enzyme and that of Xenopus laevis. In the latter species, the D3 cDNA was identified because the mRNA increased markedly in association with $T_{3}$-induced tadpole metamorphosis. This suggests it provides a control mechanism to block excessive $T_{3}$ formation during metamorphosis (17). Presumably, a similar purpose is served by the presence of D3 in human placenta. Our results show that, despite only $73 \%$ similarity and the presence of a 12 amino acid insert in $\mathrm{hD3}$, the catalytic activities of human and Xenopus enzymes are virtually identical. The $K_{\mathrm{m}}$ for 5 deiodination of $\mathrm{T}_{3}(1 \mathrm{nM})$ is within the physiological range of circulating $T_{3}$ concentrations thus indicating the biological relevance of D3 activity. Since we were able to covalently label the transiently expressed protein in a saturable and specific fashion with $\mathrm{BrAcT}_{3}$ we could quantitate the enzyme turnover number. This is two orders of magnitude lower than that for rat D1 which can explain the marked differences in sensitivity of the reaction to PTU inhibition despite the fact that they both contain selenium in the active site (34). The functional analyses of the $3^{\prime}$ ut sequences of D3 mRNA indicate that it is one of the most potent SECIS elements yet identified and that it differs in certain respects from those previously examined. Thus the cloning and functional analysis of human D3 provides the background for both a better comprehension of human maternal-fetal physiology as well as further insights into the biology of mammalian selenoprotein synthesis.

\section{Acknowledgments}

We thank our colleague Dr. Nagaoki Toyoda for his help with the affinity labeling experiments. D. Salvatore is a student of Dottorato di Ricerca in Scienze Endocrinologiche e del Metabolismo, University of Naples, Italy. S. C. Low is supported by a personal fellowship from the European Molecular Biology Organization.

This work was supported by National Institutes of Health grants DK36256, DK42271, and HD09020.

\section{References}

1. Abuid, J., D. A. Stinson, and P. R. Larsen. 1973. Serum triiodothyronine and thyroxine in the neonate and the acute increases in these hormones following delivery. J. Clin. Invest. 52:1195-1199.

2. Thorpe-Beeston, J. G., K. H. Nicolaides, and A. M. McGregor. 1992. Fetal thyroid function. Thyroid. 2:207-217.

3. Contempre, B., E. Jauniaux, R. Calvo, D. Jurkovic, S. Campbell, and G. Morreale de Escobar. 1993. Detection of thyroid hormones in human embryonic cavities during the first trimester of pregnancy. J. Clin. Endocrinol. \& Metab. 77:1719-1722.

4. Burrow, G. N., D. A. Fisher, and P. R. Larsen. 1994. Mechanisms of disease: maternal and fetal thyroid function. N. Engl. J. Med. 331:1072-1078.

5. Larsen, P. R., J. E. Silva, and M. M. Kaplan. 1981. Relationships between circulating and intracellular thyroid hormones: physiological and clinical implications. Endocr. Rev. 2:87-102.

6. Kaplan, M. M. 1986. Regulatory influences on iodothyronine deiodination in animal tissues. In Thyroid Hormone Metabolism. G. Hennemann, editor. Marcel Dekker, Inc., New York. 231-253.

7. St. Germain, D. L. 1994. Iodothyronine Deiodinases. Trends Endocrinol. Metab. 5:36-42.

8. Leonard, J. L., and T. J. Visser. 1986. Biochemistry of deiodination. In Thyroid Hormone Metabolism. G. Hennemann, editor. Marcel Dekker, Inc., New York. 189-229.

9. Klein, A. H., C. J. Hobel, J. Sack, and D. A. Fisher. 1978. Effect of intraamniotic fluid thyroxine injection on fetal serum and amniotic fluid iodothyronine concentrations. J. Clin. Endocrinol. \& Metab. 47:1034-1037.

10. Berry, M. J., L. Banu, and P. R. Larsen. 1991. Type I iodothyronine deiodinase is a selenocysteine-containing enzyme. Nature (Lond.). 349:438-440.

11. Mandel, S. J., M. J. Berry, J. D. Kieffer, J. W. Harney, R. L. Warne, and P. R. Larsen. 1992. Cloning and in vitro expression of the human selenoprotein, type I iodothyronine deiodinase. J. Clin. Endocrinol. \& Metab. 75:1133-1139.

12. Toyoda, N., J. W. Harney, M. J. Berry, and P. R. Larsen. 1994. Identification of critical amino acids for $3,5^{\prime}, 3^{\prime}$-triiodothyronine deiodination by human type 1 deiodinase based on comparative functional-structural analyses of the human, dog, and rat enzymes. J. Biol. Chem. 269:20329-20334.

13. Arthur, J. R., F. Nicol, and G. J. Beckett. 1990. Hepatic iodothyronine 5'-deiodinase. The role of selenium. Biochem. J. 272:537-540.

14. Meinhold, H., A. Campos-Barros, B. Walzog, R. Kohler, F. Muller, and D. Behne. 1993. Effects of selenium and iodine deficiency on Type I, Type II 
and Type III iodothyronine deiodinases and circulating thyroid hormones in the rat. Exp. Clin. Endocrinol. 101:87-93.

15. Santini, F., I. J. Chopra, R. E. Hurd, D. H. Solomon, and G. N. Teco. 1992 A study of the characteristics of the rat placental iodothyronine 5-monodeiodinase: evidence that is distinct from the rat hepatic iodothyronine 5'-monodeiodinase. Endocrinology. 130:2325-2332.

16. Chanoine, J. P., S. Alex, S. Stone, S. L. Fang, I. Veronikis, J. L. Leonard, and L. E. Braverman. 1993. Placental 5-deiodinase activity and fetal thyroid hormone economy are unaffected by selenium deficiency in the rat. Pediatr. Res. 34:288-292.

17. St. Germain, D. L., R. A. Schwartzman, W. Croteau, A. Kanamori, Z Wang, D. D. Brown, and V. A. Galton. 1994. A thyroid hormone-regulated gene in Xenopus laevis encodes a type III iodothyronine 5-deiodinase. Proc. Natl. Acad. Sci. USA. 91:7767-7771.

18. Berry, M. J., L. Banu, Y. Chen, S. J. Mandel, J. D. Kieffer, J. W. Harney, and P. R. Larsen. 1991. Recognition of UGA as a selenocysteine codon in type I deiodinase requires sequences in the $3^{\prime}$ untranslated region. Nature (Lond.). 353:273-276

9. Ausubel, F. M., R. Brent, R. E. Kingston, D. D. Moore, J. G. Seidman J. A. Smith, and K. Struhl. 1987. Current Protocols in Molecular Biology. John Wiley and Sons, Inc., New York. 4.6.1-4.6.10.

20. Aruffo, A., and B. Seed. 1987. Molecular cloning of a CD28 cDNA by a high-efficiency COS cell expression system. Proc. Natl. Acad. Sci. USA. 84:85738577.

21. Gossen, M., and H. Bujard. 1992. Tight control of gene expression in mammalian cells by tetracycline-responsive promoters. Proc. Natl. Acad. Sci. USA. 89:5547-5551.

22. Leinfelder, W., K. Forchhammer, B. Veprek, E. Zehelein, and A. Bock 1990. In vitro synthesis of selenocysteinyl-tRNA $\mathrm{UCA}_{\mathrm{CA}}$ : involvement and characterization of the selD gene product. Proc. Natl. Acad. Sci. USA. 87:543-547.

23. Low, S. C., J. W. Harney, and M. J. Berry. 1995. Cloning and functional characterization of human selenophosphate synthetase, an essential component of selenoprotein synthesis. J. Biol. Chem. 270:21659-21664.

24. Brent, G. A., P. R. Larsen, J. W. Harney, R. J. Koenig, and D. D. Moore. 1989. Functional characterization of the rat growth hormone promoter element required for induction by thyroid hormone with and without a co-transfected $\beta$ type thyroid hormone receptor. J. Biol. Chem. 264:178-182.

25. Brent, G. A., J. W. Harney, Y. Chen, R. L. Warne, D. D. Moore, and P. R. Larsen. 1989. Mutations of the rat growth hormone promoter which increase and decrease response to thyroid hormone define a consensus thyroid hormone response element. Mol. Endocrinol. 3:1996-2004.

26. Berry, M. J., A. L. Maia, J. D. Kieffer, J. W. Harney, and P. R. Larsen 1992. Substitution of cysteine for selenocysteine in type I iodothyronine deiodinase reduces the catalytic efficiency of the protein but enhances its translation. Endocrinology. 131:1848-1852.

27. Galton, V. A., and A. Hiebert. 1987. Hepatic iodothyronine 5-deiodinase activity in Rana catesbeiana tadpoles at different stages in the life cycle. Endocrinology. 121:42-47.
28. Snedecor, G. W., and W. G. Cochran. 1967. Statistical Methods. The Iowa State University Press, Ames, Iowa. 258-296.

29. Mol, J. A., R. Docter, G. Hennemann, and T. J. Visser. 1984. Modification of rat liver iodothyronine 5'-deiodinase activity with diethylpyrocarbonate and rose bengal: evidence for an active site histidine residue. Biochem. Biophys. Res. Commun. 120:28-36.

30. Berry, M. J., J. W. Harney, T. Ohama, and D. L. Hatfield. 1994. Selenocysteine insertion or termination: factors affecting UGA codon fate and complementary anticodon:codon mutations. Nucleic Acids Res. 22:3753-3759.

31. Berry, M. J., and P. R. Larsen. 1992. The role of selenium in thyroid hormone action. Endocr. Rev. 13:207-219.

32. Berry, M. J., L. Banu, J. W. Harney, and P. R. Larsen. 1993. Functiona characterization of the eukaryotic SECIS elements which direct selenocysteine insertion at UGA codons. EMBO (Eur. Mol. Biol. Organ.) J. 12:3315-3322.

33. Santini, F., R. E. Hurd, and I. J. Chopra. 1992. A study of metabolism of deaminated and sulfoconjugated iodothyronines by rat placental iodothyronine 5monodeiodinase. Endocrinology. 131:1689-1694.

34. Berry, M. J., J. D. Kieffer, J. W. Harney, and P. R. Larsen. 1991. Selenocysteine confers the biochemical properties of the type I iodothyronine deiodinase J. Biol. Chem. 266:14155-14158.

35. Schoenmakers, C. H. H., I. G. A. J. Pigmans, and T. J. Visser. 1995. Investigation of type I and type III iodothyronine deiodinases in rat tissues using $N$-bromoacetyl-iodothyronine affinity labels. Mol. Cell Endocrinol. 107:173-180.

36. Toyoda, N., M. J. Berry, J. W. Harney, and P. R. Larsen. 1995. Topological analysis of the integral membrane protein, type I iodothyronine deiodinase (D1) J. Biol. Chem. 270:12310-12318.

37. Kaplan, M. M. and K. A. Yakoski. 1980. Maturational patterns of iodothyronine phenolic and tyrosyl ring deiodinase activities in rat cerebrum, cerebellum, and hypothalamus. J. Clin. Invest. 67:1204-1214.

38. Karmarkar, M. G., D. Prabarkaran, and M. M. Godbole. 1993. 5 '-Monodeiodinase activity in developing human cereberal cortex. Am. J. Clin. Nutr 57:291S-294S.

39. Mori, K., K. Yoshida, T. Kayama, N. Kaise, H. Fukazawa, Y. Kiso, K. Kikuchi, Y. Aizawa, and K. Abe. 1993. Thyroxine 5-deiodinase in human brain tumors. J. Clin. Endocrinol. \& Metab. 77:1198-1202.

40. Leonard, J. L., D. M. Ekenbarger, S. J. Frank, A. P. Farwell, and J. Kohrle. 1991. Localization of type I iodothyronine 5 '-deiodinase to the basolateral plasm membrane in renal cortical epithelial cells. J. Biol. Chem. 266:11262-11269.

41. Larsen, P. R., and M. J. Berry. 1994. Type I iodothyronine deiodinase: unexpected complexities in a simple deiodination reaction. Thyroid. 4:357-362.

42. Axley, M. J., A. Bock, and T. C. Stadtman. 1991. Catalytic properties of an Escherichia coli formate dehydrogenase mutant in which sulfur replaces selenium. Proc. Natl. Acad. Sci. USA. 88:8450-8454.

43. Beckett, G. J., D. A. MacDougal, F. Nicol, and J. R. Arthur. 1989. Inhibition of type I and II iodothyronine deiodinase activity in rat liver, kidney and brain produced by selenium deficiency. Biochem. J. 259:887-892.

44. Chanoine, J. P., L. E. Braverman, A. P. Farwell, M. Safran, S. Alex, S Dubord, and J. L. Leonard. 1993. The thyroid gland is a major source of circulating T3 in the rat. J. Clin Invest. 91:2709-2713. 